\title{
Molecular Determinants of Pyrantel Selectivity in Nicotinic Receptors
}

\author{
Mariana Bartos, Diego Rayes, and Cecilia Bouzat \\ Instituto de Investigaciones Bioquímicas, Universidad Nacional del Sur-Consejo Nacional de Investigaciones Científicas y \\ Técnicas, Bahía Blanca, Argentina
}

Received May 4, 2006; accepted July 5, 2006

\begin{abstract}
Nicotinic receptors (acetylcholine receptors, AChRs) play key roles in synaptic transmission throughout the nervous system. AChRs mediate neuromuscular transmission in nematodes, and they are targets for antiparasitic drugs. The anthelmintic agents levamisole and pyrantel, which are potent agonists of nematode muscle AChRs, are partial agonists of mammalian muscle AChRs. To further explore the structural basis of the differential activation of AChR subtypes by anthelmintics, we studied the activation of $\alpha 7 \mathrm{AChRs}$ using the high-conductance form of the $\alpha 7-5$-hydroxytryptamine-3A receptor, which is a good model for pharmacological studies involving the extracellular region of $\alpha 7$. Macroscopic and single-channel current recordings show that levamisole is a weak agonist of $\alpha 7$. It is interesting that pyrantel is a more potent agonist of $\alpha 7$ than
\end{abstract}

acetylcholine (ACh). To identify determinants of this differential activation, we replaced residues of the complementary face of the binding site by the homologous residues in the muscle $\varepsilon$ subunit and evaluated changes in activation. The mutation Q57G does not affect the activation by either ACh or levamisole. However, it increases $\mathrm{EC}_{50}$ values and decreases the maximal response to pyrantel. Kinetic analysis shows that gating of the mutant channel activated by pyrantel is profoundly impaired. The decreased sensitivity of $\alpha 7-Q 57 G$ to pyrantel agrees with its weak action at muscle AChRs, indicating that when glycine occupies position 57 , as in the mammalian muscle AChR, pyrantel behaves as a partial agonist. Thus, position 57 located at the complementary face of the binding site plays a key role in the selective activation of AChRs by pyrantel.
Cysteine-loop receptors are pentameric ligand-gated ion channels that play key roles in chemical synapses throughout the nervous system. In vertebrates, the cysteine-loop receptor superfamily consists of two families of cation-selective channels: the nicotinic acetylcholine (AChR) and the 5-hydroxytryptamine type 3 receptors $\left(5 \mathrm{HT}_{3} \mathrm{Rs}\right)$; and two families of anionic channels: the $\gamma$-aminobutyric acid and the glycine receptors (Le Novére and Changeux, 2001; Lester et al., 2004). In invertebrates, this superfamily also includes $\gamma$-aminobutyric acid-gated cationic channels and ACh-, serotonin-, glutamate-, and histamine-gated chloride channels (Jones and Sattelle, 2003; Putrenko et al., 2005).

AChR subunits are classified as $\alpha$, which contain a disulfide bridge involved in the recognition and binding of agonists, and non- $\alpha$ subunits, which lack this motif. To date, several $\alpha$ and non- $\alpha$ subunits have been identified. Receptors can be either heteromeric, composed of $\alpha$ and non- $\alpha$ subunits, or homomeric, composed of five identical $\alpha$ subunits. Each

This work was supported by grants from CONICET, Universidad Nacional del Sur, FONCYT and a fellowship from John Simon Guggenheim Memorial Foundation (to C.B.).

Article, publication date, and citation information can be found at http://molpharm.aspetjournals.org.

doi:10.1124/mol.106.026336. subunit is divided into an N-terminal or ligand-binding domain and a transmembrane region. The binding sites are located at the interface between two subunits (Brejc et al., 2001; Sine, 2002). Results from affinity labeling and sitedirected mutagenesis studies on $\mathrm{AChR}$, which were later supported by the structural model of the acetylcholine binding protein (Brejc et al., 2001), revealed that the binding site is formed by three (called loops A-C) and four (called loops D-G) linearly separated regions of the $\alpha$ (principal face) and the adjacent subunit (complementary face), respectively. The principal face is always formed by the $\alpha$ subunit, whereas the complementary face is formed by the $\gamma$ or $\varepsilon$ and $\delta$ subunits in the muscle AChR and by the $\alpha$ subunit in the homomeric $\alpha 7$ AChR (Sine, 2002).

The mammalian muscle AChR has a composition of $\alpha_{2} \beta \gamma \delta$ in embryonic and denervated muscle and $\alpha_{2} \beta \varepsilon \delta$ in adult muscle. Nematode muscle AChRs are of considerable interest because they are targets for antiparasitic drugs. The freeliving helminth Caenorhabditis elegans, which is a model for the study of parasitic nematodes, has one of the largest and most diverse AChR gene families known (Jones and Sattelle, 2003). The subunit composition of each AChR subtype is not known. 
Levamisole and pyrantel are two widely used anthelmintic drugs that cause hypercontraction of body wall muscles of nematode worms. The efficacy of these drugs is based on their ability to act as full agonists of AChRs in nematodes (Martin et al., 1996). In contrast, they are very low-efficacy agonists of the mammalian muscle AChR (Rayes et al., 2001, 2004). The molecular basis of this selectivity has not been fully elucidated. To further understand the structural basis of the differential activation of AChR subtypes by anthelmintic agents we here explore how these drugs activate homomeric $\alpha 7$ AChRs.

Studies were carried out using the high-conductance form of the $\alpha 7-5 \mathrm{HT}_{3 \mathrm{~A}}$ receptor, which has two advantages that make it an excellent model for pharmacological studies of $\alpha 7$ receptors: it shows, in contrast to $\alpha 7$, high surface expression in mammalian cells; and it allows currents to be detected at the single-channel level (Rayes et al., 2005). Our results reveal that, as in the mammalian muscle AChR, levamisole is a very low-efficacy agonist of $\alpha 7 \mathrm{AChRs}$. However, pyrantel acts at $\alpha 7$ as a more potent and equally efficacious agonist with respect to ACh. To identify the structural basis of the different actions of pyrantel at muscle and $\alpha 7 \mathrm{AChRs}$, we performed site-directed mutagenesis at candidate residues. Because residues that form the principal face of the binding site are highly conserved between $\alpha 7$ and muscle AChRs (Sine, 2002), we studied residues at the complementary face of the binding site. Our results show that position 57 located at the complementary binding site face is a main determinant of the selectivity of pyrantel for AChR subtypes.

These studies provide new insights into the differential activation of AChR subtypes by anthelmintic agents and identify specific differences that can be exploited therapeutically. They also help to understand how parasites develop resistance to antiparasitic drugs.

\section{Materials and Methods}

Site-Directed Mutagenesis and Expression of $\alpha 7-5 \mathrm{HT}_{3 \mathrm{~A}} \mathrm{Re}-$ ceptors. Mutant subunits were constructed using the QuikChange Site-Directed Mutagenesis Kit (Stratagene, La Jolla, CA) and were confirmed by restriction enzyme analysis and sequencing. The highconductance form (HC) of the $\alpha 7-5 \mathrm{HT}_{3 \mathrm{~A}}$ receptor (Eisele et al., 1993) was constructed as described in Rayes et al. (2005). In brief, three arginine residues responsible for the low conductance of the serotonin type $3 \mathrm{~A}$ receptor $\left(5 \mathrm{HT}_{3 \mathrm{~A}}\right)$ were mutated as described before (Kelley et al., 2003). BOSC cells were transfected with $\alpha 7-5 \mathrm{HT}_{3 \mathrm{~A}} \mathrm{HC}$ subunit cDNAs using calcium phosphate precipitation, as described previously (Bouzat et al., 1994, 2000, 2002). Cells were used for single-channel and macroscopic current measurements 1 or 2 days after transfection.

Patch-Clamp Recordings and Kinetic Analysis. Single-channel recordings were obtained in the cell-attached configuration (Hamill et al., 1981) at a membrane potential of $-70 \mathrm{mV}$ and at $20^{\circ} \mathrm{C}$, essentially as described before (Bouzat et al., 2004; Rayes et al., 2005). The bath and pipette solutions contained $142 \mathrm{mM} \mathrm{KCl}, 5.4$ $\mathrm{mM} \mathrm{NaCl}, 0.2 \mathrm{mM} \mathrm{CaCl}_{2}$, and $10 \mathrm{mM}$ HEPES, $\mathrm{pH}$ 7.4. Solutions free of magnesium and with low-calcium were used to minimize channel block by divalent cations. Patch pipettes were pulled from 7052 capillary tubes (Garner Glass, Claremont, CA) and coated with Sylgard (Dow Corning, Midland, MI). ACh and anthelmintic drugs were added to the pipette solution.

Single-channel currents were recorded using an Axopatch $200 \mathrm{~B}$ patch-clamp amplifier (Axon Instruments, Sunnyvale, CA), digitized at $5-\mu$ s intervals with the PCI-6111E interface (National Instru- ments, Austin, TX), recorded to the computer hard disk using the program Acquire (Bruxton Corporation, Seattle, WA), and detected by the half amplitude threshold criterion using the program TAC 4.0.10 (Bruxton Corporation) at a final bandwidth of $10 \mathrm{kHz}$ (Bouzat et al., 2000). Open-, closed-, and burst-duration histograms were plotted using a logarithmic abscissa and a square root ordinate (Sigworth and Sine, 1987) and fitted to the sum of exponential functions by maximum likelihood using the program TACFit (Bruxton Corporation). Bursts were identified as a series of closely spaced openings preceded and followed by closed intervals longer than a critical duration, which was taken as the point of intersection of the second and third closed components in the closed-time histogram. The burst duration and number of openings per burst were determined from the burst-duration histogram, in which the component corresponding to isolated openings is clearly distinguished from that corresponding to bursts.

For whole-cell recordings, the pipette solution contained $140 \mathrm{mM}$ $\mathrm{KCl}, 5 \mathrm{mM}$ EGTA, $5 \mathrm{mM} \mathrm{MgCl}_{2}$, and $10 \mathrm{mM}$ HEPES, $\mathrm{pH} 7.3$. Extracellular solution contained $150 \mathrm{mM} \mathrm{NaCl}, 5.6 \mathrm{mM} \mathrm{KCl}, 0.5 \mathrm{mM}$ $\mathrm{CaCl}_{2}$, and $10 \mathrm{mM}$ HEPES, pH 7.3. A series of applications of extracellular solution containing ACh, levamisole, or pyrantel was applied to the cell as described before (Liu and Dilger, 1991; Spitzmaul et al., 2001). Macroscopic currents were filtered at $5 \mathrm{kHz}$ and digitized at $20 \mathrm{kHz}$. Data analysis was performed using the IgorPro software (WaveMetrics Inc., Lake Oswego, OR). The ensemble mean current was calculated for 5 to 10 individual current traces. Mean currents were usually fitted by a single exponential function: $I_{(\mathrm{t})}=I_{0}$ $\exp \left(-t / \tau_{\mathrm{d}}\right)+I_{\infty}$, where $I_{0}$ and $I_{\infty}$ are the peak and the steady-state current values, respectively, and $\tau_{\mathrm{d}}$ is the decay time constant. Current records were aligned with each other at the point at which the current had increased to $50 \%$ of its maximum level. $\mathrm{EC}_{50}$ and Hill coefficient values were calculated by nonlinear regression analysis using the Hill equation: $I / I_{\max }=1 /\left[1+\left(\mathrm{EC}_{50} / L\right)^{n} \mathrm{H}\right]$, where $\mathrm{EC}_{50}$ is the agonist concentration that elicits the half-maximal response, $n_{\mathrm{H}}$ is the Hill coefficient, and $L$ is the agonist concentration.

Kinetic analysis was performed as described before (Wang et al., 1997; Bouzat et al., 2000, 2002; Rayes et al., 2005). The analysis was restricted to bursts of channel openings, each reflecting the activity of a single channel. For the kinetic analysis, bursts containing three or more openings were selected. Typically, the burst terminator was $2 \mathrm{~ms}$. For each recording, kinetic homogeneity was determined by selecting bursts on the basis of distributions of mean open duration, mean closed duration, and open probability (Wang et al., 1997; Bouzat et al., 2000; Rayes et al., 2005). Bursts showing mean open channel durations, mean closed channel durations, and open probabilities within 2 S.D. of the mean of the major component were selected. Typically, more than $90 \%$ of bursts were selected. The resulting open and closed intervals from single patches were analyzed according to kinetic schemes using an interval-based maximum likelihood algorithm that corrects for missed events and computes error limits of the fitted rate constants (Qin et al., 1996) (http://www.qub.buffalo.edu; QuB suite, State University of New York, Buffalo, NY). A dead time of $30 \mu$ s was imposed in all recordings. Probability density functions of open and closed durations were calculated from the fitted rate constants and instrumentation dead time and superimposed on the experimental dwell-time histogram as described by Qin et al. (1996).

\section{Results}

\section{Activation of $\alpha 7-5 \mathrm{HT}_{3 \mathrm{~A}} \mathrm{HC}$ by Pyrantel and Levamisole}

Macroscopic Currents Elicited by Anthelmintic Agents. Levamisole and pyrantel are full agonists of the levamisole-sensitive subtype of nematode muscle AChRs (Martin et al., 1996; Richmond and Jorgensen, 1999), but they are extremely low-efficacy agonists of mammalian muscle AChRs (Rayes et al., 2001, 2004). To understand the 
structural basis of the differential sensitivity among AChR subtypes to anthelmintics, we studied the activation of $\alpha 7$ AChRs by these agents. We used the high-conductance form of the chimera $\alpha 7-5 \mathrm{HT}_{3 \mathrm{~A}}\left(\alpha 7-5 \mathrm{HT}_{3 \mathrm{~A}} \mathrm{HC}\right)$, which allows detection of activity at the single-channel level (Rayes et al., 2005).

To evaluate the efficacy of levamisole and pyrantel for activating $\alpha 7-5 \mathrm{HT}_{3 \mathrm{~A}} \mathrm{HC}$, we first recorded macroscopic currents elicited by $1 \mathrm{mM} \mathrm{ACh}$, levamisole, and pyrantel (Fig. 1A). As shown in the figure, levamisole is unable to elicit current responses, similarly to what is observed in mammalian muscle AChRs. In contrast, pyrantel is capable of activating $\alpha 7-5 \mathrm{HT}_{3 \mathrm{~A}}$ receptors. Moreover, the amplitude of the current elicited by pyrantel is similar to that generated by $\mathrm{ACh}$ in the same patch. By the relationship between the peak current and pyrantel concentration, an $\mathrm{EC}_{50}$ value of $44 \pm 3$ $\mu \mathrm{M}\left(n_{\mathrm{H}}=2.6 \pm 0.4\right)$ is obtained (Fig. 1B). This value is five times lower than that calculated for $\mathrm{ACh}$ responses $\left(\mathrm{EC}_{50}\right.$ $\mathrm{ACh}=205 \pm 10 \mu \mathrm{M} ; n_{\mathrm{H}}=2.43 \pm 0.06$; Rayes et al., 2005). These results suggest that, in contrast to its weak action at

\section{A}

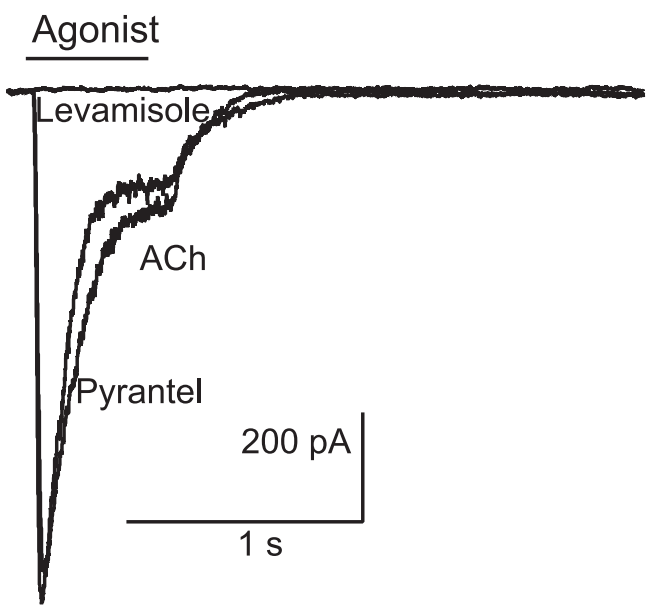

B

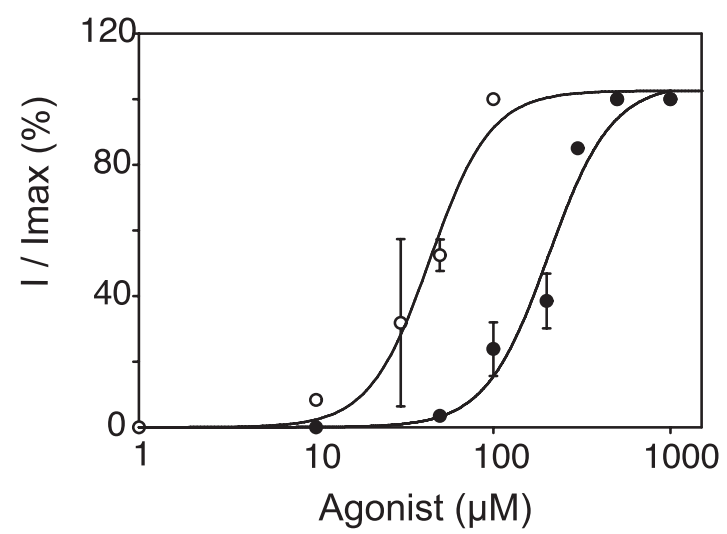

Fig. 1. Macroscopic currents activated by ACh, pyrantel, and levamisole. $\mathrm{A}$, currents recorded in the whole-cell configuration in response to $1 \mathrm{mM}$ ACh, $1 \mathrm{mM}$ levamisole, and $1 \mathrm{mM}$ pyrantel. The solid bar indicates the duration of the exposure to agonist. Each trace represents the average of three to four applications of agonist. Membrane potential, $-50 \mathrm{mV}$. B, dose-response curves for $\mathrm{ACh}(\bigcirc)$ and pyrantel (○). Each point is an average of three to five determinations, with the error bars representing the S.D. of the mean value. Curves are fits to the Hill equation. mammalian muscle AChRs, pyrantel is a high-efficacy and potent agonist of $\alpha 7 \mathrm{AChRs}$.

Single-Channel Currents Elicited by Anthelmintic Agents. The activation of $\alpha 7-5 \mathrm{HT}_{3 \mathrm{~A}} \mathrm{HC}$ by anthelmintics was also evaluated at the single-channel level at a membrane potential of $-70 \mathrm{mV}$ (Fig. 2). Single-channel currents are observed at $\mathrm{ACh}$ concentrations greater than $30 \mu \mathrm{M}$ (Rayes et al., 2005). At $500 \mu \mathrm{M}$ ACh, channel currents appear either as isolated openings flanked by long closings or as bursts of several openings in quick succession (Fig. 2). Open-time histograms can be fitted by three components whose mean durations and relative areas are the following: $\tau 1=6.20 \pm 0.20$ $\mathrm{ms}(0.50 \pm 0.10) ; \tau 2=0.60 \pm 0.30 \mathrm{~ms}(0.16 \pm 0.01) ;$ and $\tau 3=$ $140 \pm 20 \mu \mathrm{s}(0.35 \pm 0.08)$ (Fig. 2). The areas and durations of these components remain almost unaffected at ACh concentrations greater than $30 \mu \mathrm{M}$. At $30 \mu \mathrm{M}$, the brief events are significantly dominant (Rayes et al., 2005).

Single-channel currents are observed at levamisole concentrations higher than $500 \mu \mathrm{M}$ (Fig. 2). Openings are extremely infrequent and significantly briefer than those activated by ACh. Open-time histograms can be fitted by a single component whose duration is 50 -fold briefer than that of the slowest component observed at $500 \mu \mathrm{M} \mathrm{ACh}(127 \pm 25 \mu \mathrm{s})$. Due to the extremely low number of openings, histograms had to be constructed by adding data from at least three different recordings. In contrast, single-channel currents are readily detected in the presence of pyrantel at concentrations as low as $5 \mu \mathrm{M}$. Open-time distributions of $\alpha 7-5 \mathrm{HT}_{3 \mathrm{~A}} \mathrm{HC}$ activated by $10 \mu \mathrm{M}$ pyrantel show two main components, whose durations and relative areas are the following: $2.60 \pm 0.55 \mathrm{~ms}$ $(0.60 \pm 0.04)$ and $240 \pm 50 \mu \mathrm{s}(0.40 \pm 0.04)$ (Fig. 2). The slight changes in the open components at $10 \mu \mathrm{M}$ pyrantel with respect to those observed with $\mathrm{ACh}$ are due to the fact that pyrantel also acts as an open-channel blocker (see below). As observed for ACh, at the lowest pyrantel concentration at which channels can be detected $(5 \mu \mathrm{M})$, the briefest open component is the predominant one (180 $\pm 20 \mu \mathrm{s}$; relative area, $0.60 \pm 0.07$ ).

Short bursts of several openings in quick succession are typically observed during activation of $\alpha 7-5 \mathrm{HT}_{3 \mathrm{~A}}$ receptors (Rayes et al., 2005). The duration of bursts recorded at 500 $\mu \mathrm{M}$ ACh $(14.8 \pm 3.9 \mathrm{~ms})$ and at $10 \mu \mathrm{M}$ pyrantel $(10.6 \pm 1.9$ $\mathrm{ms})$ are not statistically different $(p>0.05, n=6)$.

\section{Kinetic Analysis of $\alpha 7-5 \mathrm{HT}_{3 \mathrm{~A}}$ Channels Activated and Blocked by Levamisole or Pyrantel}

Rates for Levamisole and Pyrantel Blockade of AChActivated $\alpha 7-5 \mathrm{HT}_{3 \mathrm{~A}}$ Receptors Estimated by SingleChannel Kinetic Analysis. We have shown previously that pyrantel and levamisole act as open-channel blockers of the mammalian muscle AChRs (Rayes et al., 2001, 2004) and that nicotinic agonists act as open-channel blockers of $\alpha 7$ $5 \mathrm{HT}_{3 \mathrm{~A}} \mathrm{HC}$ (Rayes et al., 2005). We therefore examined channel blockade of $\alpha 7-5 \mathrm{HT}_{3 \mathrm{~A}}$ by pyrantel and levamisole. In this receptor, block is produced at the $5 \mathrm{HT}_{3 \mathrm{~A}}$ pore. Increasing pyrantel concentration from 10 to $300 \mu \mathrm{M}$ leads to a clear flickering effect and a concentration-dependent decrease of the mean open time. At $300 \mu \mathrm{M}$, open-time histograms are fitted by a single component of $165 \pm 30 \mu \mathrm{s}$ (Fig. 3A). Because openings in the presence of levamisole are very infrequent, we evaluated its action as an open-channel blocker of $\alpha 7$ $5 \mathrm{HT}_{3 \mathrm{~A}}$ channels activated by $500 \mu \mathrm{M}$ ACh. As described for 
pyrantel, increasing levamisole concentration progressively displaces the open-time histogram of ACh-activated channels to briefer durations (Fig. 3B). The relative area of the briefest component of the closed-time histogram increases as a function of the anthelmintic concentration for both pyrantel and levamisole (Fig. 3, A and B). The mean duration of this component, which does not change with concentration, is $42 \pm 4$ and $30 \pm 3 \mu \mathrm{s}$ for pyrantel and levamisole, respectively.

In summary, channel activity in the presence of pyrantel or levamisole bears all the hallmarks of open-channel block: 1) concentration-dependent decrease in mean open time; 2 ) concentration-dependent increase in the fractional area of the block component; and 3) constant mean duration of the blocked intervals across all blocker concentrations.

To kinetically describe the block by anthelmintic agents, we performed kinetic analysis of $\alpha 7-5 \mathrm{HT}_{3 \mathrm{~A}}$ activated by $\mathrm{ACh}$ and blocked by levamisole or pyrantel. We have shown recently that burst analysis of $\alpha 7-5 \mathrm{HT}_{3 \mathrm{~A}}$ receptor gives information about its activation kinetics (Rayes et al., 2005). Open- and closed-time distributions from bursts activated by $\mathrm{ACh}$ are well described by the sum of two exponentials, indicating brief and long openings and closings within each burst. We have also shown that activation within bursts can be well described by a cyclic scheme containing two open and two closed states (Scheme 1).

Here, each open state is connected to two closed states and vice versa (Rayes et al., 2005). To estimate the rates of block of ACh-activated channels by levamisole and pyrantel, we fitted Scheme 2 to the closed and open intervals of bursts recorded in the presence of $500 \mu \mathrm{M}$ ACh and 100 to $500 \mu \mathrm{M}$ levamisole, or $1 \mathrm{mM} \mathrm{ACh}$ and 1 to $5 \mu \mathrm{M}$ pyrantel.

Scheme 2 is an extension of Scheme 1, containing two additional blocked states (O1B and $\mathrm{O} 2 \mathrm{~B}$ ) connected to each open state (O1 and O2). Given that levamisole is an extremely weak agonist of this receptor and that the infrequent openings elicited by this drug do not occur in bursts, we can ensure that activation is mediated only by ACh. In contrast, because pyrantel is a full agonist of this receptor, we used only low concentrations of this drug (1-5 $\mu \mathrm{M})$ to ensure that activation is elicited by ACh. Moreover, the analysis is performed with kinetically homogenous bursts. Therefore, data from either anthelmintic-activated or heteroliganded receptors, which should show different kinetics from those of AChactivated receptors (Steinbach and Chen, 1995; Akk et al., 2005), would be discarded during the selection of bursts.
Open

\section{Counts}

$500 \mu \mathrm{M}$ ACh
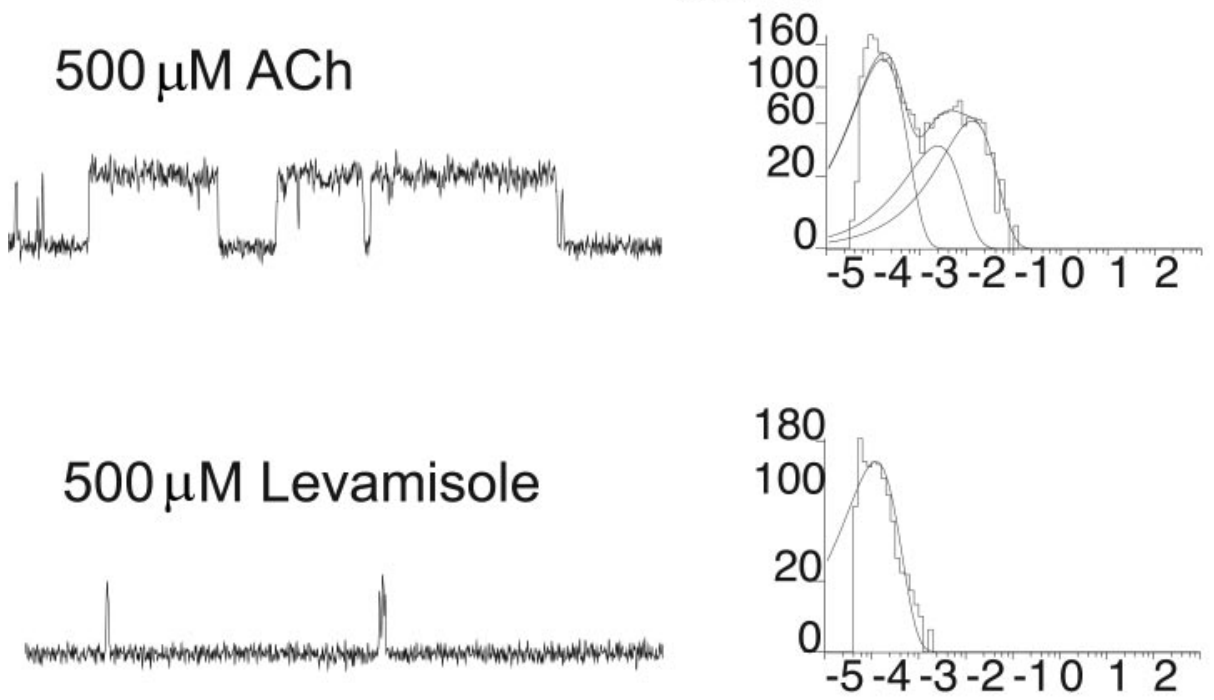

\section{$500 \mu \mathrm{M}$ Levamisole}

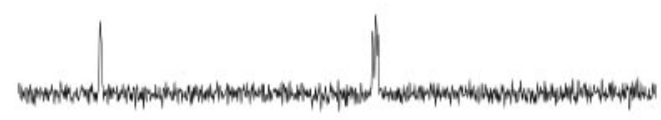

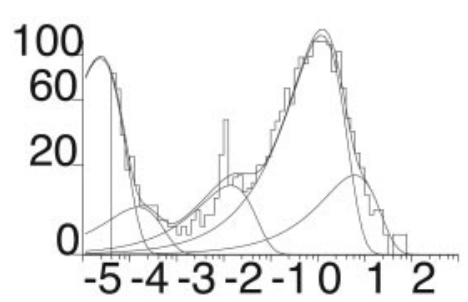

\section{Closed}
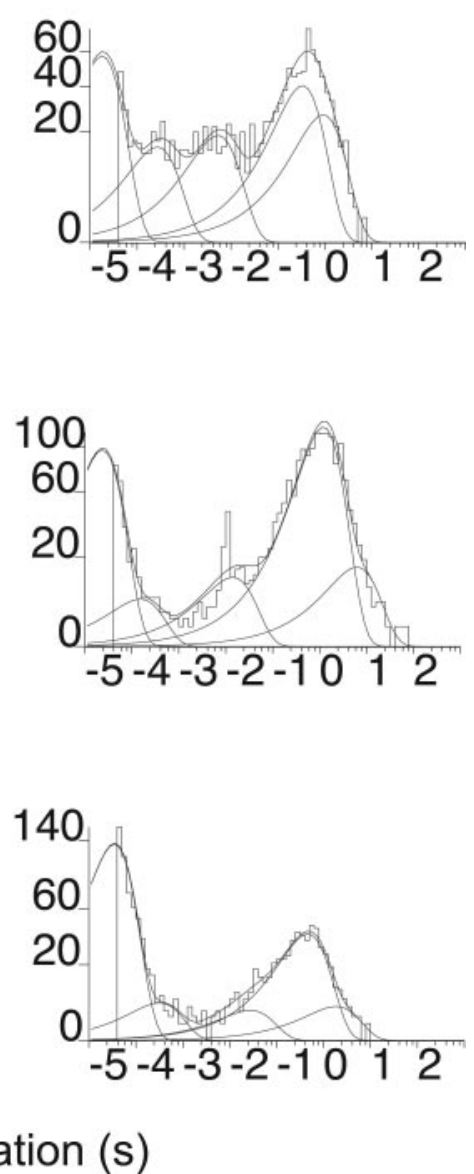

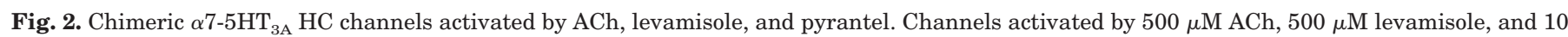

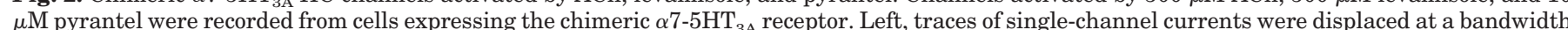

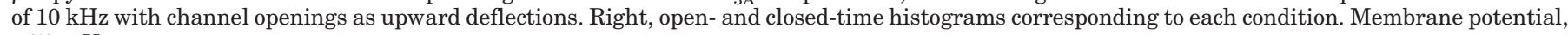
$-70 \mathrm{mV}$. 
Open

A Pyrantel

$10 \mu \mathrm{M}$

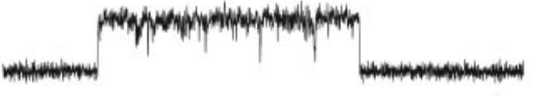

$5 \mathrm{pA}$

$100 \mu \mathrm{M}$

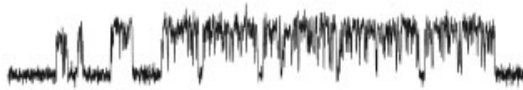

$300 \mu \mathrm{M}$

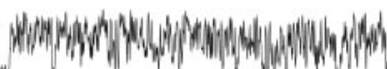

\section{B}

$500 \mu \mathrm{M} \mathrm{ACh}$

Levamisole

$0 \mu \mathrm{M}$<smiles>CC1CCC[C@@H]1C</smiles>

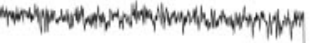

Imimumintur

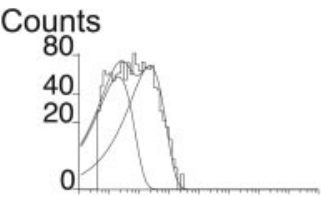

Closed
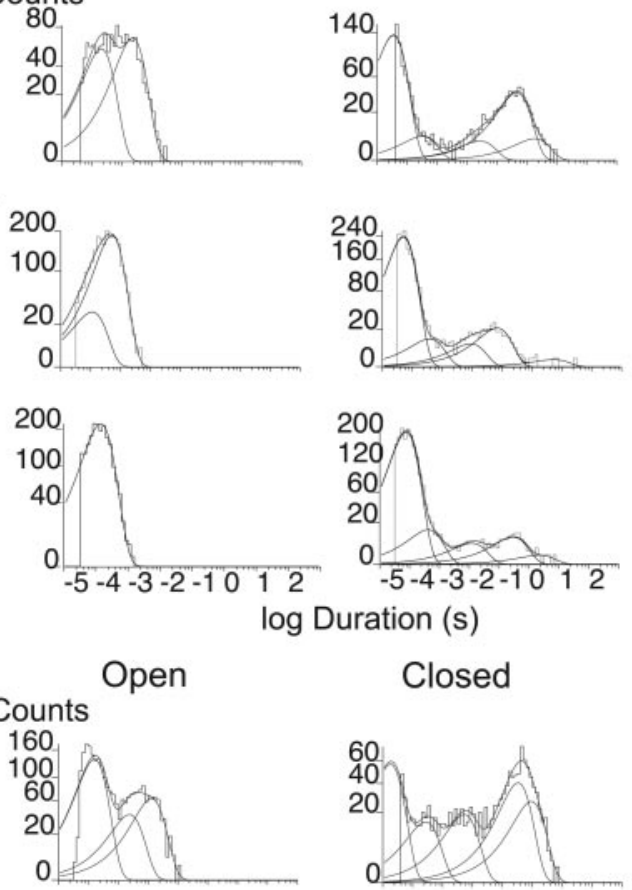

log Duration (s)

$5 \mathrm{pA}$

$100 \mu \mathrm{M}$
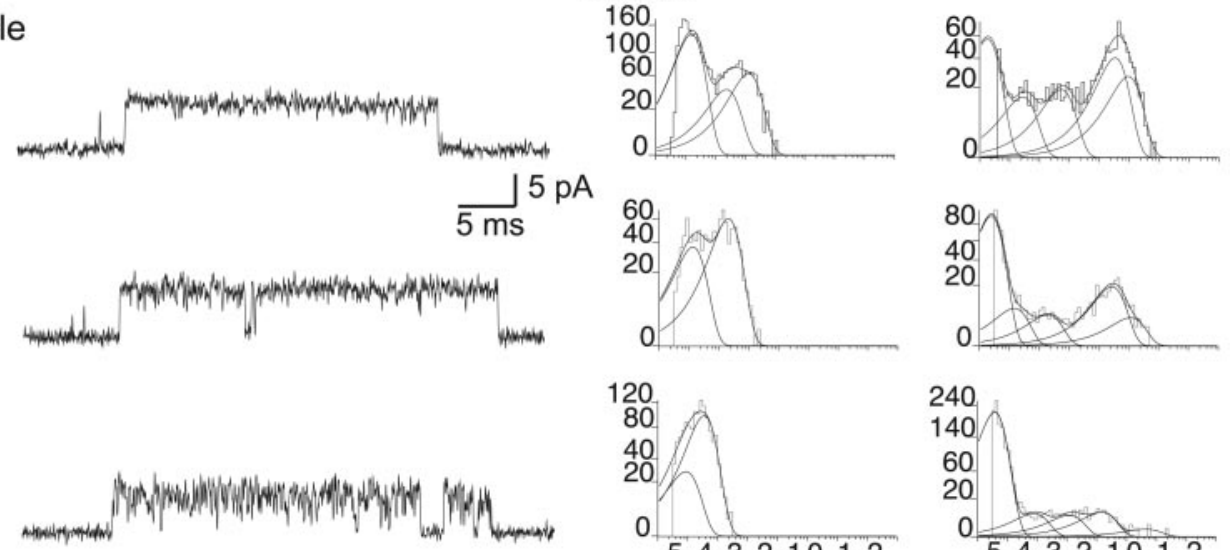

C
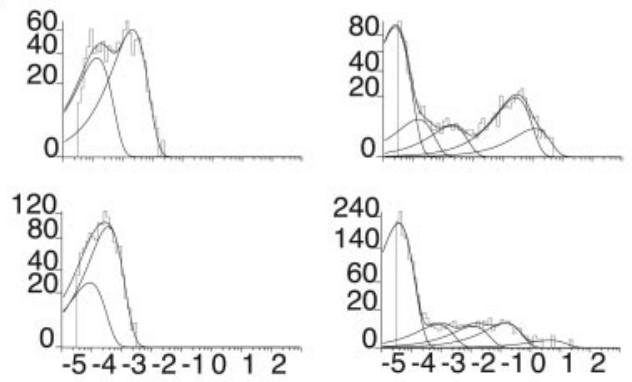

log Duration (s)

Pyrantel
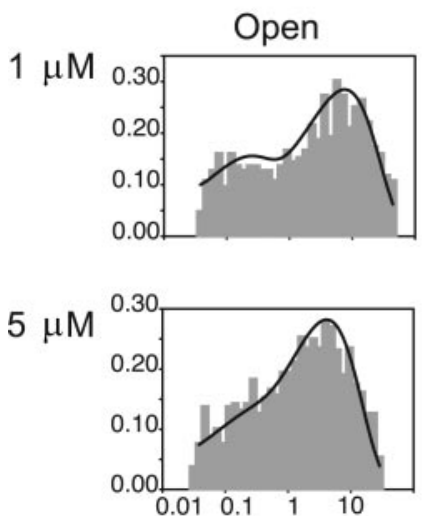
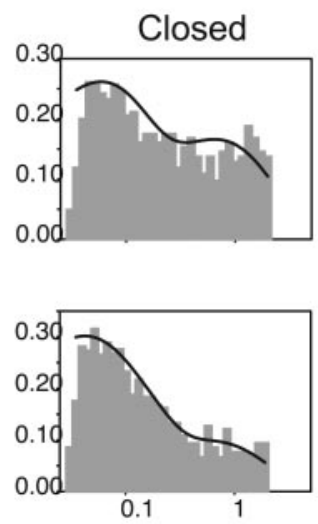

Levamisole
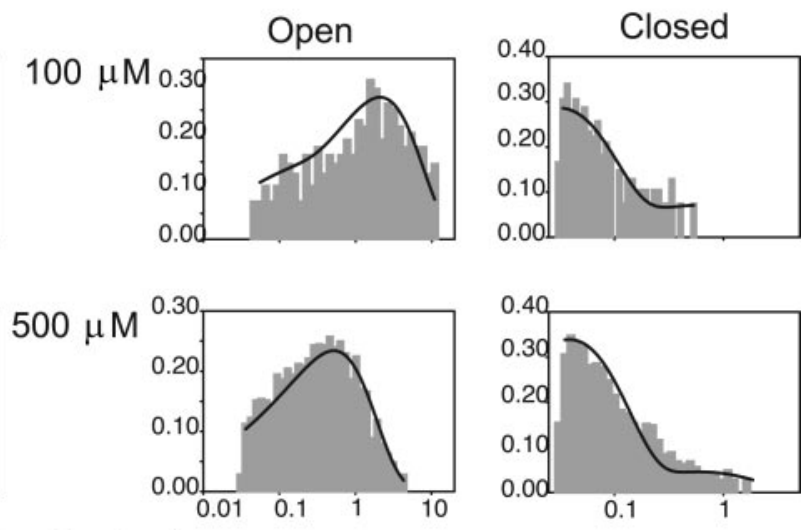

Duration (ms)

Fig. 3. Open-channel block produced by anthelmintic agents. A, single-channel currents of $\alpha 7-5 \mathrm{HT}_{3 \mathrm{~A}}$ as a function of pyrantel concentration. Left, channel traces recorded in the presence of 10,100 , and $300 \mu \mathrm{M}$ pyrantel. Right, open- and closed-duration histograms corresponding to the different conditions. B, combined action of ACh and levamisole on $\alpha 7-5 \mathrm{HT}_{3 \mathrm{~A}}$. Left, traces of currents recorded in the presence of $500 \mu \mathrm{M}$ ACh and 100 or 500 $\mu \mathrm{M}$ levamisole. Right, open- and closed-time histograms of the corresponding recordings. Currents were displaced at a bandwidth of $10 \mathrm{kHz}$ with channel openings as upward defections. Membrane potential, $-70 \mathrm{mV}$. C, kinetic analysis of $\alpha 7-5 \mathrm{HT}_{3 \mathrm{~A}}$ receptors blocked by anthelmintic agents. Channels were recorded in the presence of $1 \mathrm{mM}$ ACh and pyrantel $(1$ and $5 \mu \mathrm{M})$ or $500 \mu \mathrm{M}$ ACh and levamisole $(100$ and $500 \mu \mathrm{M})$. Bursts were selected for kinetic analysis as described under Materials and Methods and the burst terminator was set to 2 ms. Open- and closed-duration histograms are shown with probability density functions derived from fitting Scheme 2 to open and closed intervals (smooth curves). Histograms were constructed with the selected bursts, and the ordinates correspond to the square root of the fraction of events per bin. 
Given that channel block is not observed at $1 \mathrm{mM} \mathrm{ACh}$ (Rayes et al., 2005), we can ensure that block is only produced by levamisole or pyrantel.

We constrained the rate constants between closed and open states to their previously determined values for ACh (Rayes et al., 2005; Table 1). We assumed that blocking and unblocking rates are the same for the two open states (O1 and 02 ). We simultaneously fitted the scheme to data obtained at multiple levamisole or pyrantel concentrations (Table 1). The probability density functions resulting from the kinetic analysis adequately fitted the experimental histograms (Fig. 3C), indicating that Scheme 2 provides a good description of the anthelmintic block of ACh-activated channels. The resulting estimates for blocking rates are the following: $k_{+\mathrm{b}}=10 \pm 0.30$ and $49 \pm 2.40 \mu \mathrm{M}^{-1} \mathrm{~s}^{-1}$ for levamisole and pyrantel, respectively; $k_{-\mathrm{b}}=32,000 \pm 800$ and $15,400 \pm 640 \mathrm{~s}^{-1}$ for levamisole and pyrantel, respectively. Considering the estimated rates for $k_{+\mathrm{b}}$ and $k_{-\mathrm{b}}$, the $K_{\mathrm{d}}$ values $\left(k_{-\mathrm{b}} / k_{+\mathrm{b}}\right)$ for the blocking process are $3.2 \mathrm{mM}$ and 310 $\mu \mathrm{M}$ for levamisole and pyrantel, respectively. On the basis of the $K_{\mathrm{d}}$ value for pyrantel, a decrease in the peak current

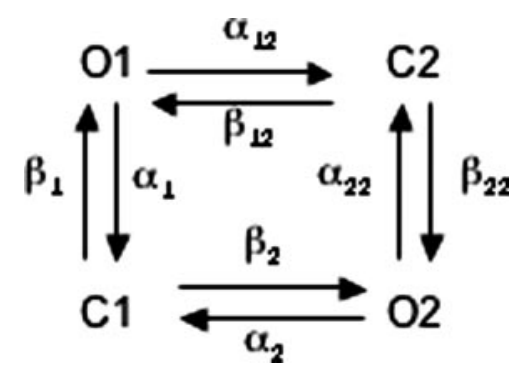

Scheme 1. ACh activation of $\alpha 7-5 \mathrm{HT}_{3 \mathrm{~A}}$ receptors. Within bursts, each open state is connected to two closed states, and vice versa.

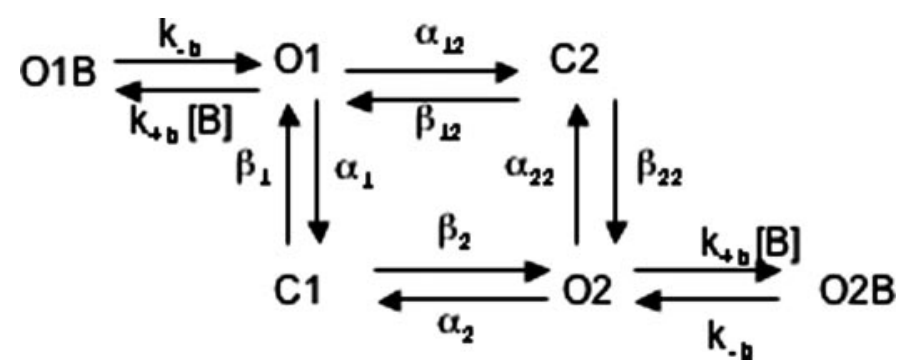

Scheme 2. Activation and block of $\alpha 7-5 \mathrm{HT}_{3 \mathrm{~A}}$ receptors. This is an extension of Scheme 1, containing two additional blocked states connected to each open state. should be observed at $1 \mathrm{mM}$ pyrantel (Fig. 1). However, only at $2 \mathrm{mM}$ did we detect a $36 \pm 5 \%$ reduction of the peak current. Thus, a quantitative correlation between the $K_{\mathrm{d}}$ calculated from the single channel data and the reduction of the macroscopic currents is not observed. Discrepancies between results obtained from cell-attached and whole-cell recordings have been reported previously (Akk et al., 2004, 2005). The reasons for these discrepancies are not understood. The possible explanations include the patch excision, exposure of the receptor to different monovalent inorganic cations, statistical and biological variability, and experimental artifacts (Akk et al., 2004, 2005).

Kinetic Analysis of Pyrantel-Activated $\alpha$ 7-5HT $_{3 \mathrm{~A}}$ Receptors. To estimate the rate constants for activation of $\alpha 7-5 \mathrm{HT}_{3 \mathrm{~A}}$ by pyrantel, and after having assessed that Scheme 2 can well describe activation and blockade, we fitted the open and closed times of channels activated by 10 and 50 $\mu \mathrm{M}$ pyrantel to this scheme. In this analysis, we constrained the blocking and unblocking rates to the values determined above for pyrantel block of ACh-activated $\alpha 7-5 \mathrm{HT}_{3 \mathrm{~A}}$ receptors.

The estimated values for pyrantel activation rates are detailed in Table 1 . The main difference with respect to ACh activation is observed in $\alpha_{12}$. The fact that this rate is very slow when pyrantel is the agonist ( $\sim 40,000$-fold slower than for $\mathrm{ACh}$ ) indicates that long closings within a burst occur very rarely. In close correspondence, a thorough inspection of the recordings shows very few long closings within bursts, in contrast to what is observed when ACh is the agonist (Rayes et al., 2005).

As a control, we constrained the rates for the blocking process to those determined as described above and fitted Scheme 2 to data obtained in the presence of $1 \mathrm{mM} \mathrm{ACh}$ and $5 \mu \mathrm{M}$ pyrantel. No changes in ACh-activation rates were observed with respect to those estimated in the absence of pyrantel. We can therefore ensure that the differences in the estimated rates for pyrantel- and $\mathrm{ACh}$ activation do not arise from fitting the data to different schemes either containing (Scheme 2) or lacking (Scheme 1) blocked states.

\section{Residues Involved in the Activation of $\alpha 7-5 \mathrm{HT}_{3 \mathrm{~A}}$ by Pyrantel}

Because pyrantel is a weak agonist of the mammalian muscle AChR but a potent agonist of $\alpha 7-5 \mathrm{HT}_{3 \mathrm{~A}}$, we studied the structural basis of such a difference by mutating residues that are probably involved in agonist binding. Residues of the

\section{TABLE 1}

Kinetic parameters of $\alpha 7-5 \mathrm{HT}_{3 \mathrm{~A}}$ and $\alpha 7$-Q57G mutant channels activated by ACh and pyrantel

Values are results of simultaneous fits of Scheme 1 (ACh) and Scheme 2 (pyrantel) to data from different patches for each condition. For control and mutant receptors, ACh concentrations were 50 and $500 \mu \mathrm{M}$. Pyrantel concentrations were 10 and $50 \mu \mathrm{M}$ for $\alpha 7-5 \mathrm{HT}_{3 \mathrm{~A}}$ and 60 and $70 \mu \mathrm{M}$ for $\alpha 7-\mathrm{Q} 57 \mathrm{G}-5 \mathrm{HT}_{3 \mathrm{~A}} \cdot k_{+\mathrm{b}}$ and $k_{-\mathrm{b}}$ were constrained to the values determined in the presence of ACh.

\begin{tabular}{|c|c|c|c|c|}
\hline \multirow{2}{*}{ Schemes 1 and 2} & \multicolumn{2}{|c|}{$\alpha 7-5 \mathrm{HT}_{3 \mathrm{~A}}$} & \multicolumn{2}{|c|}{$\alpha 7-\mathrm{Q} 57 \mathrm{G}-5 \mathrm{HT}_{3 \mathrm{~A}}$} \\
\hline & $\mathrm{ACh}$ & Pyrantel & $\mathrm{ACh}$ & Pyrantel \\
\hline$\beta 1\left(\mathrm{~s}^{-1}\right)$ & $10,400 \pm 1700$ & $10,100 \pm 1300$ & $9400 \pm 820$ & $2.5 \pm 1.8$ \\
\hline$\alpha 1\left(\mathrm{~s}^{-1}\right)$ & $7800 \pm 1000$ & $4400 \pm 2000$ & $5800 \pm 420$ & $25 \pm 12$ \\
\hline$\beta 2\left(\mathrm{~s}^{-1}\right)$ & $37,500 \pm 3000$ & $38,000 \pm 5100$ & $22,750 \pm 1900$ & $50,000 \pm 10,000$ \\
\hline$\alpha 2\left(\mathrm{~s}^{-1}\right)$ & $330 \pm 20$ & $450 \pm 90$ & $170 \pm 20$ & $970 \pm 470$ \\
\hline$\beta 12\left(\mathrm{~s}^{-1}\right)$ & $1500+120$ & $1860 \pm 470$ & $1130 \pm 115$ & $1630 \pm 800$ \\
\hline$\alpha 12\left(\mathrm{~s}^{-1}\right)$ & $6100 \pm 760$ & $0.15 \pm 0.10$ & $5500 \pm 940$ & $26 \pm 14$ \\
\hline$\beta 22\left(\mathrm{~s}^{-1}\right)$ & $540 \pm 70$ & $12 \pm 8$ & $1130 \pm 130$ & $1.2 \pm 0.9$ \\
\hline$\alpha 22\left(\mathrm{~s}^{-1}\right)$ & $25 \pm 3$ & $20 \pm 6$ & $\begin{array}{c}56 \pm 6 \\
56 \pm 6\end{array}$ & $62 \pm 36$ \\
\hline$k_{+\mathrm{b}}\left(\mu \mathrm{M}^{-1} \mathrm{~s}^{-1}\right)$ & & 49 & & $\begin{array}{r}02-50 \\
49\end{array}$ \\
\hline$k_{-\mathrm{b}}^{+\mathrm{b}}\left(\mathrm{s}^{-1}\right)$ & & 15,400 & & 15,400 \\
\hline
\end{tabular}


principal face that have been shown to be involved in agonist binding (Sine, 2002) are highly conserved between $\alpha 7$ and $\alpha 1$ subunits. Less conservation is found at the complementary face of the binding site (Fig. 4). We therefore replaced residues of this side of $\alpha 7-5 \mathrm{HT}_{3 \mathrm{~A}}$ by the homologous residues in the $\varepsilon$ subunit, which contributes to one of the binding sites in the muscle AChR (Brejc et al., 2001). We constructed the following mutant receptors: $\alpha 7-\mathrm{Q} 57 \mathrm{G}, \alpha 7-\mathrm{N} 111 \mathrm{Y}, \alpha 7-\mathrm{Q} 117 \mathrm{~T}$, and $\alpha 7-$ G167A and evaluated channel activity elicited by pyrantel (Fig. 5).

The minimum concentrations of both ACh $(30 \mu \mathrm{M})$ and pyrantel $(5 \mu \mathrm{M})$ at which channel currents can be detected and the channel properties are not affected by the $\alpha 7-\mathrm{G} 167 \mathrm{~A}$ mutation (Fig. 5). In the $\alpha 7-\mathrm{N} 111 \mathrm{Y}$ and $\alpha 7-\mathrm{Q} 117 \mathrm{~T}$ mutants, the minimum concentration to elicit single-channel currents increases for both $\mathrm{ACh}$ and pyrantel with respect to the control chimera. In these mutants, channels appear at approximately 2- and 3-fold higher concentrations of $\mathrm{ACh}$ and pyrantel, respectively, than in the control $\alpha 7-5 \mathrm{HT}_{3 \mathrm{~A}}(60 \mu \mathrm{M}$ for ACh and $15 \mu \mathrm{M}$ for pyrantel). The mean open time, mean closed time and mean burst duration do not change in the mutants with respect to control $\alpha 7-5 \mathrm{HT}_{3 \mathrm{~A}}$ for both agonists (Fig. 5). It can therefore be concluded that $\alpha 7-\mathrm{N} 111 \mathrm{Y}$ and $\alpha 7-\mathrm{Q} 117 \mathrm{~T}$ mutations do not affect gating kinetics; they only produce a slight and quantitatively similar decrease in the sensitivity for activation by both agonists. Thus, these residues do not contribute significantly to the differential activation between pyrantel and ACh among AChR subtypes.

When Gln57 is replaced by glycine, which is the equivalent residue at the $\varepsilon$ subunit, the potency of pyrantel to activate $\alpha 7-5 \mathrm{HT}_{3 \mathrm{~A}}$ decreases significantly. Single-channel openings can be observed only at concentrations greater than $50 \mu \mathrm{M}$ (instead of $5 \mu \mathrm{M}$ ). The duration and relative areas of the slowest component of the open time distribution corresponding to the entire recording are similar to those of the control chimera at each pyrantel concentration $[810 \pm 30 \mu \mathrm{s}(0.64 \pm$

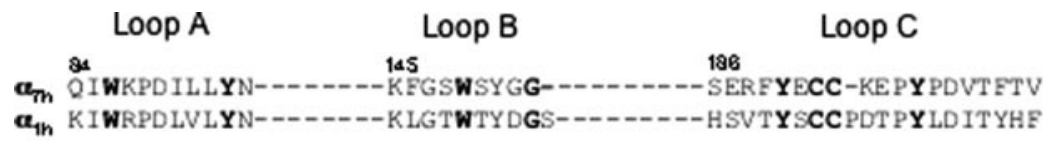

Loop D Loop E Loop F

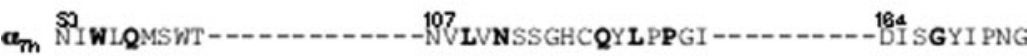

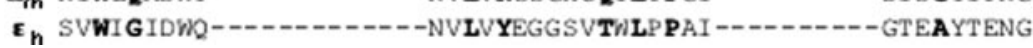

Fig. 4. Sequence alignment of AChR subunits. Sequence alignment of $\alpha 7$ and $\alpha 1$ human subunits showing residues located at the principal face of the binding site and of $\alpha 7$ and $\varepsilon$ subunits showing residues at the complementary face. The sequences were aligned with ClustalW (1.81). Residues involved in the binding site are shown in boldface type (Brejc et al., 2001).

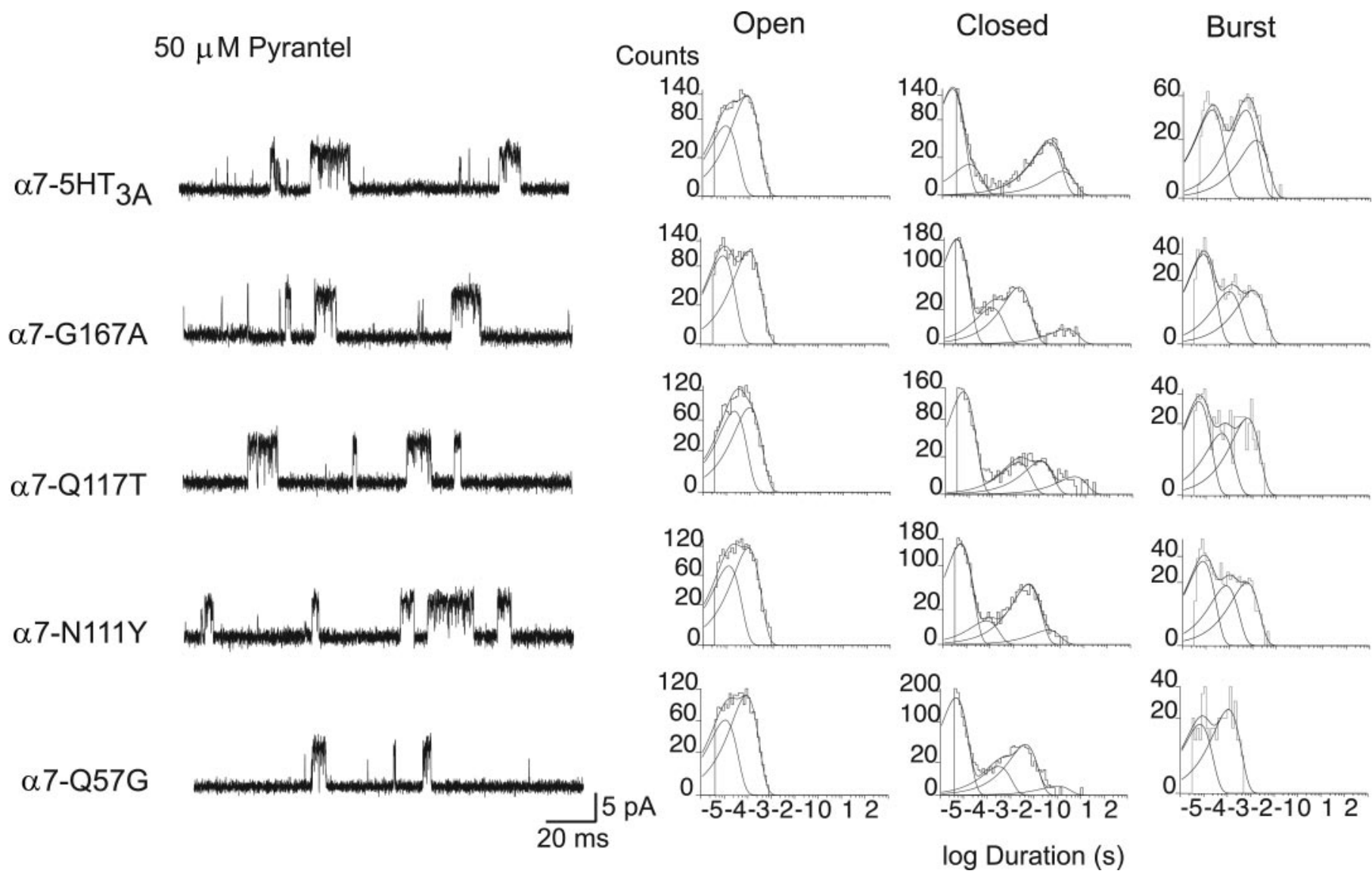

Fig. 5. Channels activated by $50 \mu \mathrm{M}$ pyrantel were recorded from cells expressing mutant $\alpha 7-5 \mathrm{HT}_{3 \mathrm{~A}}$ receptors. Left, traces of currents are displayed at a bandwidth of $10 \mathrm{kHz}$ with channel openings as upward deflections. Membrane potential, -70 mV. Right, open-, closed-, and burst-duration histograms corresponding to channels activated by $50 \mu \mathrm{M}$ pyrantel. 
$0.01)$ and $800 \pm 90 \mu \mathrm{s}(0.73 \pm 0.02), 530 \pm 30 \mu \mathrm{s}(0.66 \pm 0.05)$ and $560 \pm 10 \mu \mathrm{s}(0.70 \pm 0.05)$, and $100 \pm 10 \mu \mathrm{s}(1)$ and $120 \pm$ $20 \mu \mathrm{s}$ (1) for mutant and control at 50,100, and $500 \mu \mathrm{M}$ pyrantel, respectively].

In contrast, the duration of bursts of openings decreases 3 -fold in the mutant receptor $(11.63 \pm 2.02$ and $4.10 \pm 0.41$ $\mathrm{ms}$ for the control and mutant $\alpha 7-5 \mathrm{HT}_{3 \mathrm{~A}}$, respectively). Such reduction is accompanied by a reduction in the number of openings per burst $(20.5 \pm 9$ and $6.5 \pm 0.2$ events per burst for the control and Q57G mutant chimera activated by $50 \mu \mathrm{M}$ pyrantel, respectively). To discard that the briefer bursts observed in the mutant were isolated openings blocked by pyrantel, we recorded channels at $+70 \mathrm{mV}$. At this membrane potential, channel block is significantly reduced. However, openings still occur in bursts $(4.8 \pm 0.7$ openings per burst).

It is interesting to note that when the mutant Q57G chimera is activated by $\mathrm{ACh}$, no differences in the minimum concentration required to detect single events and in the mean open time, mean closed time, and mean burst duration are observed with respect to those of the control chimera. At $500 \mu \mathrm{M} \mathrm{ACh}$, the mean durations and relative areas of the open components are the following: $\tau 1=6.50 \pm 0.80 \mathrm{~ms}$ $(0.25 \pm 0.01) ; \tau 2=0.80 \pm 0.50 \mathrm{~ms}(0.16 \pm 0.05)$; and $\tau 3=$ $90 \pm 10 \mu \mathrm{s}(0.56 \pm 0.02)$; and the mean burst duration is $14.3 \pm 6.4 \mathrm{~ms}$. These results show that the mutation Q57G selectively alters activation by pyrantel.

We examined activation of Q57G mutant by levamisole, but channels were detected only in 10 to $20 \%$ of the patches of transfected cells. The few channels detected were similar to those of the control chimera. Given the low activity in both the control and mutant $\alpha 7-5 \mathrm{HT}_{3 \mathrm{~A}}$ receptors activated by levamisole, it is not possible to determine at this step whether this position also affects levamisole activation.

To determine the overall changes in pyrantel activation produced by the mutation $\mathrm{Q} 57 \mathrm{G}$, we measured macroscopic currents (Fig. 6). The $\mathrm{EC}_{50}$ for pyrantel, calculated by the dose-response curve, is 2-fold greater than that of the control chimera ( $77 \pm 4 \mu \mathrm{M}$ instead of $44 \pm 3 \mu \mathrm{M})$. The Hill coefficient decreases from $2.60 \pm 0.4$ (control chimera) to $1.83 \pm 0.02$ in the mutant chimera $(p<0.05, n=4)$, thus indicating an impairment of channel gating (Colquhoun, 1998). The peak current induced by a saturating concentration of pyrantel $(500 \mu \mathrm{M})$ is $61 \pm 4 \%$ of that elicited by $500 \mu \mathrm{M}$ ACh, showing that the maximum response is also affected. A similar decrease in the peak current is observed at $+100 \mathrm{mV}$ (Fig. 6). At this positive potential, openchannel block is almost undetected (Neher and Steinbach, 1978; Rayes et al., 2004). This observation together with the fact that a reduction in peak current by channel block is not observed in the control chimera at $500 \mu \mathrm{M}$ pyrantel (see above) indicate that the reduction in the maximum response is originated from a reduced efficacy and not from channel block.

In contrast, neither the $\mathrm{EC}_{50}$ value $(220 \pm 20 \mu \mathrm{M})$ nor the Hill coefficient $(2.34 \pm 0.4)$ changed for ACh. As in the control chimera, levamisole is unable to elicit current responses in the mutant Q57G chimera.

In conclusion, the mutation $\mathrm{Q} 57 \mathrm{G}$ does not affect activation by ACh, but it significantly decreases the potency and efficacy of pyrantel activation. This position is differentially conserved among subunits. It is glycine in mammalian $\varepsilon$ subunits, glutamic acid in $\gamma$ subunits, and glutamic acid or aspartic acid in $\delta$ subunits.

If a glutamine is found at this position, as in $\alpha 7$ receptors, pyrantel behaves as a full agonist. If a glycine occupies position 57, as in the muscle $\varepsilon$ subunit, pyrantel behaves as a partial agonist. These results indicate that position 57, located at the complementary face of the AChR binding site, is a main determinant of the different selectivity of pyrantel between muscle and $\alpha 7 \mathrm{AChRs}$.

\section{Kinetics of Activation of Q57G Mutant Receptor by Pyrantel or ACh}

To analyze the activation kinetics of the Q57G mutant, we first fitted Scheme 1 to the open and closed intervals of bursts recorded at 50 and $500 \mu \mathrm{M} \mathrm{ACh}$. As expected from the singlechannel and macroscopic current data, no changes are observed in the estimated rates for ACh activation between the control and the mutant chimera (Table 1; Fig. 7). In contrast, the kinetic analysis for pyrantel activation of the mutant

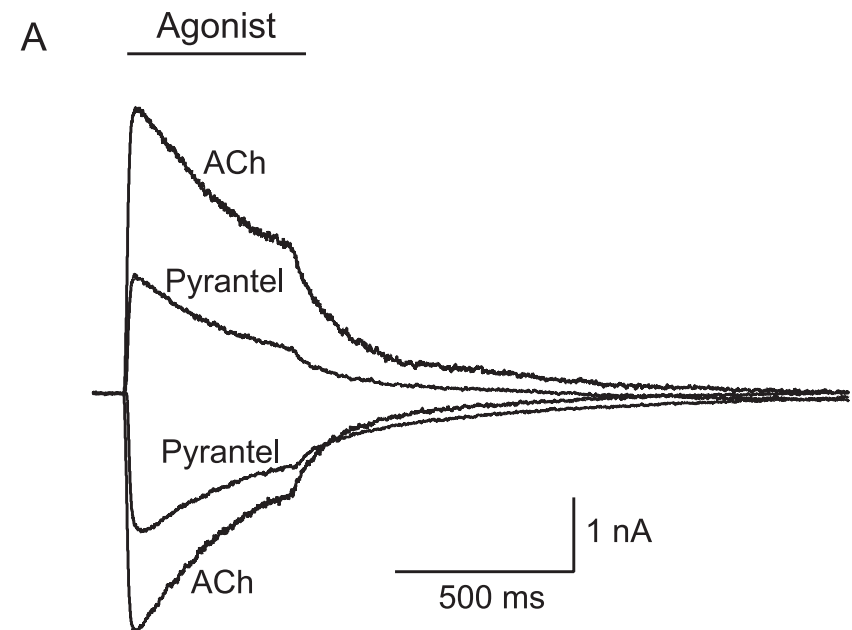

B

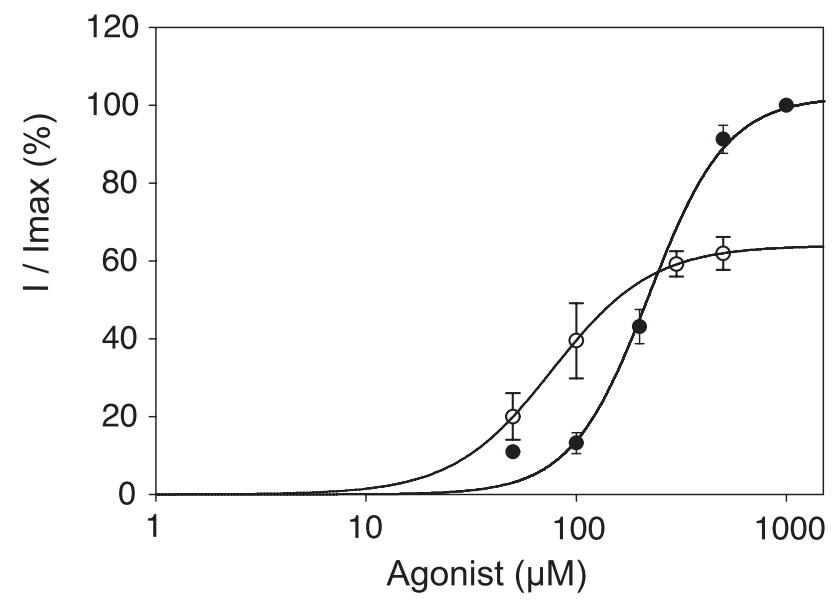

Fig. 6. Macroscopic current recordings of $\alpha 7-5 \mathrm{HT}_{3 \mathrm{~A}}$ receptors carrying the mutation $\mathrm{Q} 57 \mathrm{G}$ activated by ACh and pyrantel. A, whole-cell currents recorded in response to rapid perfusion of $500 \mu \mathrm{M}$ ACh or $500 \mu \mathrm{M}$ pyrantel. The solid bar indicates the duration of exposure to agonist. Each curve is the average of two to four agonist applications. B, doseresponse curves for ACh $(\bullet)$ and pyrantel $(\bigcirc)$. Each point in the doseresponse curves is an average of three to five determinations with the error bars representing the S.D. Curves are fits to the Hill equation. Holding potentials were -50 and $+100 \mathrm{mV}$. 
receptor reveals important differences in the estimated rate constants with respect to the control receptor (Table 1; Fig. 7). For this analysis, we fitted Scheme 2 to data obtained in the presence of 60 and $70 \mu \mathrm{M}$ pyrantel. These concentrations, which are higher than the minimum concentration at which channels can be detected $(50 \mu \mathrm{M})$, allow us to maintain channel blockade as low as possible. As shown in Fig. 7, open-time histograms constructed with the selected bursts show a main component of $690 \pm 90 \mu$ s with a relative area of $0.95 \pm 0.02$. The main changes in activation rates due to the mutation Q57G are observed in $\beta_{1}$ and $\alpha_{1}$, which are $\sim 4000$ - and $\sim 180$-fold, respectively, lower than those of the control chimera (Table 1). The kinetic analysis reveals that in this mutant activated by pyrantel, the cyclic scheme could be simplified to a linear one, containing one open state (O2), one closed state (C1), and the blocked state. Thus, in contrast to the nonmutant receptor that is able to oscillate between two different open states, the mutant receptor opens mainly to a single state. Assuming that the burst finishes by desensitization from the longest duration open state $(\mathrm{O} 2)$, the absence of a second open component may explain the reduction in the number of openings per burst. An increase in the dissociation rate, which cannot be measured by kinetic analysis in the chimeric receptor (Rayes et al., 2005), may also contribute to the decrease in the number of openings per burst. In summary, the mutation Q57G selectively impairs activation by pyrantel.

\section{Activation by Anthelmintic Agents of $\alpha 7-5 \mathrm{HT}_{3 \mathrm{~A}}$ Receptors Carrying a Mutation at Gly153, Located at the Principal Face of the Binding Site}

We have shown previously that mutation of the highly conserved Gly153 of mammalian $\alpha 1$ subunit to a glutamic acid, which is found at equivalent positions in several nematode $\alpha$ subunits, increases the efficacy of levamisole and pyrantel to activate mammalian muscle AChRs (Rayes et al., 2004). We therefore determined how this position is involved in the activation of $\alpha 7$ by pyrantel and levamisole. As shown in Fig. 8, single channels of the mutant $\alpha 7$ G153E receptor activated by pyrantel and levamisole can be detected at concentrations 5-fold lower than those required to activate the control receptor. High channel activity is observed at $100 \mu \mathrm{M}$ levamisole in the $\alpha 7-\mathrm{G} 153 \mathrm{E}$ mutant, and open-time histograms show two components $(\tau 1,795 \pm 120 \mu \mathrm{s} ; \tau 2,154 \pm 40 \mu \mathrm{s})$. Channels are observed at pyrantel concentrations as low as $1 \mu \mathrm{M}$ in the $\alpha 7-\mathrm{G} 153 \mathrm{E}$ mutant. Open-time distributions at $1 \mu \mathrm{M}$ pyrantel are fitted by three components whose durations are $5.10 \pm$ $0.71 \mathrm{~ms}, 1.04 \pm 0.21 \mathrm{~ms}$, and $105 \pm 41 \mu \mathrm{s}$. For ACh, the minimum concentration for channel detection decreases 3 -fold $(10 \mu \mathrm{M})$. Open-time histograms are similar to those of the control chimera $(\tau 1,6.80 \pm 0.20 \mathrm{~ms} ; \tau 2,0.40 \pm 0.20$ $\mathrm{ms} ; \tau 3,110 \pm 20 \mu \mathrm{s})$.

Thus, the mutation $\alpha 7-\mathrm{G} 153 \mathrm{E}$ affects activation by both $\mathrm{ACh}$ and anthelmintics, albeit changes are more pronounced for anthelmintics. In contrast, Gln57 does not contribute to ACh activation, but it significantly affects activation by pyrantel. Thus, this residue plays an important role in the selectivity for pyrantel.

To further explore the contributions of Gln57 and Gly153 to pyrantel and levamisole activation, we analyzed the double mutant Q57G-G153E. In the double-mutant receptors activated by both levamisole and $\mathrm{ACh}$, the minimum concentration required to detect single channels and the channel properties are the same as those of the single G153E mutant. Channels are detected at $10 \mu \mathrm{M}$ ACh or $100 \mu \mathrm{M}$ levamisole. For $10 \mu \mathrm{M} \mathrm{ACh}$, neither the open-time distribution $(\tau 1$, $6.80 \pm 0.40 \mathrm{~ms} ; \tau 2,0.50 \pm 0.20 \mathrm{~ms} ; \tau 3,74 \pm 11 \mu \mathrm{s})$ nor the mean burst duration $(13.3 \pm 1.5 \mathrm{~ms})$ is affected. At $100 \mu \mathrm{M}$ levamisole, open-time distributions show two components whose durations are similar to those of the G153E single mutant $(\tau 1,790 \pm 14 \mu \mathrm{s} ; \tau 2,90 \pm 4 \mu \mathrm{s})$. These results demonstrate that Gln57 does not contribute to the activation by levamisole and ACh.
$50 \mu \mathrm{M} \mathrm{ACh}$

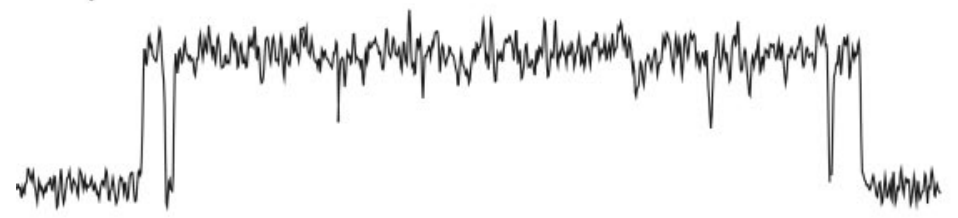

Open

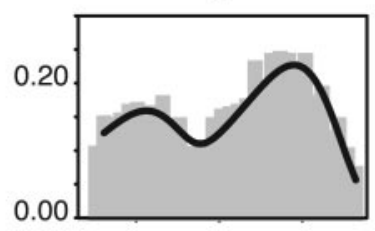

Closed

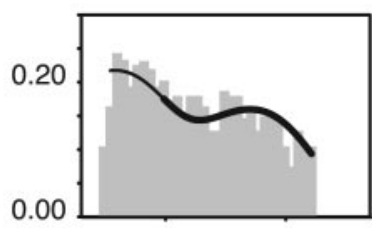

\section{$60 \mu \mathrm{M}$ Pyrantel}
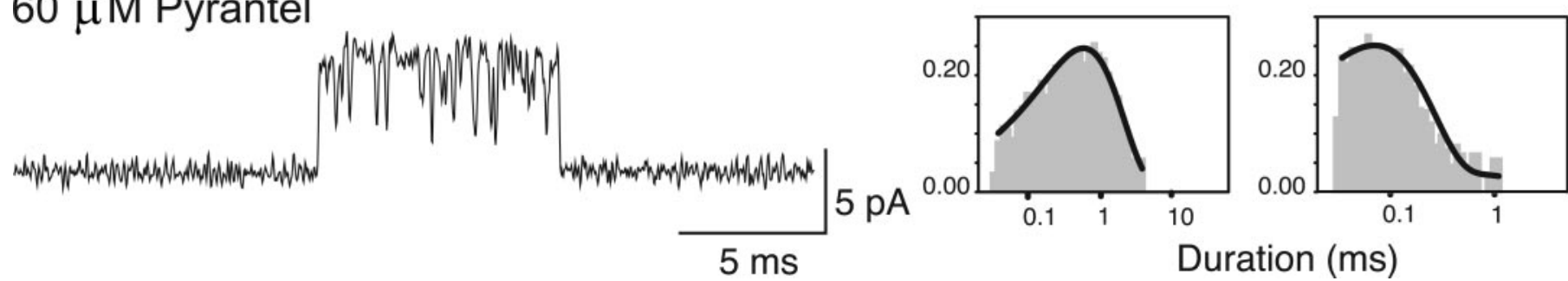

$5 \mathrm{~ms}$

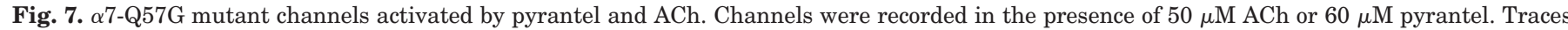

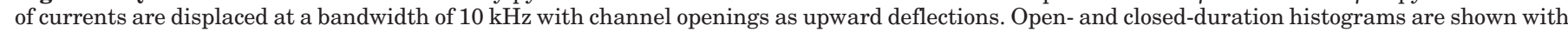

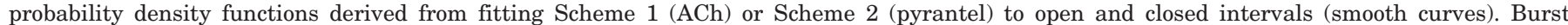

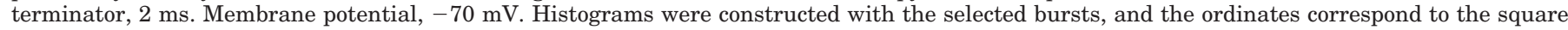
root of the fraction of events per bin. 
It is interesting that the double mutant Q57G-G153E activated by pyrantel shows an intermediate behavior between the single Q57G, which shows decreased efficacy, and G153E, which shows increased efficacy. The minimum concentration required to detect single channels is $10 \mu \mathrm{M}$, which is intermediate between that of G153E $(1 \mu \mathrm{M})$ and Q57G $(50 \mu \mathrm{M})$ mutant receptors. As described for both single mutations, no changes in the open-time components are observed with respect to the control chimera.

Taken together, our experiments demonstrate that position 153 located at the principal face is involved in the activation by $\mathrm{ACh}$, levamisole, and pyrantel whereas position 57 located at the complementary face is involved only in pyrantel activation.

\section{Discussion}

Levamisole and pyrantel are anthelmintic agents that act by disrupting neuromuscular transmission in nematodes. They are full agonists of the levamisole-sensitive AChR. In contrast, they are partial agonists of mammalian muscle AChRs (Rayes et al., 2001, 2004). Position 153 of the $\alpha$ subunit is involved in this differential selectivity (Rayes et al., 2004). To further explore determinants of such selectivity, we investigated the actions of these agents on the neuronal $\alpha 7$. We took advantage of the high-conductance form of $\alpha 7-5 \mathrm{HT}_{3 \mathrm{~A}}$ that allows the detection of single-channel events (Rayes et al., 2005). Both single-channel and macroscopic current recordings show that levamisole produces a very weak activation. It is interesting that pyrantel is a more potent agonist than $\mathrm{ACh}$ for this receptor. By replacing residues located at the complementary face of the binding site in $\alpha 7$ by the equivalent residues in the muscle $\varepsilon$ subunit, we identified Gln57 as one of the residues involved in this differential sensitivity. The same residue has been shown to have a critical role in the interaction of $\alpha 7$ with neonicotinoid insecticides, and it may be involved in the selective actions of these compounds at insect AChRs (Shimomura et al., 2002). Thus, this position seems to have a fundamental role in drug selectivity.

Differential Actions of Pyrantel and Levamisole at $\boldsymbol{\alpha} 7$ AChRs. The behavior of levamisole at $\alpha 7-5 \mathrm{HT}_{3 \mathrm{~A}}$ receptors is similar to that at mammalian muscle AChRs: it acts as an extremely low-efficacy agonist. The weak activation is revealed by the low frequency of opening events at all levamisole concentrations and the absence of macroscopic currents elicited by levamisole.

This is the first report showing that pyrantel is a full agonist of $\alpha 7 \mathrm{AChRs}$. The following lines of experimental evidence support this statement: 1) the current amplitudes are similar to those elicited by $\mathrm{ACh} ; 2$ ) the dose-response curve is displaced to lower agonist concentrations, indicating that it has indeed a higher potency than $\mathrm{ACh}$; 3) the minimum concentration that allows detection of single-channel events is 5-fold lower for pyrantel than for ACh; and 4) single-channel kinetic analysis shows similar rates for activation of $\alpha 7-5 \mathrm{HT}_{3 \mathrm{~A}}$ by pyrantel and ACh.

Kinetics of Activation of $\boldsymbol{\alpha 7 - 5 H T _ { 3 A }}$ by Pyrantel. Channel events of $\alpha 7-5 \mathrm{HT}_{3 \mathrm{~A}}$ activated by ACh appear as single openings flanked by long closings or as bursts of several openings in quick succession (Rayes et al., 2005). Bursts elicited by a saturating concentration of ACh contain brief and long openings and closings, and a cyclic scheme contain-
$10 \mu \mathrm{M}$ ACh

$\alpha 7-5 \mathrm{HT}_{3 \mathrm{~A}}$

$\alpha 7-G 153 E$
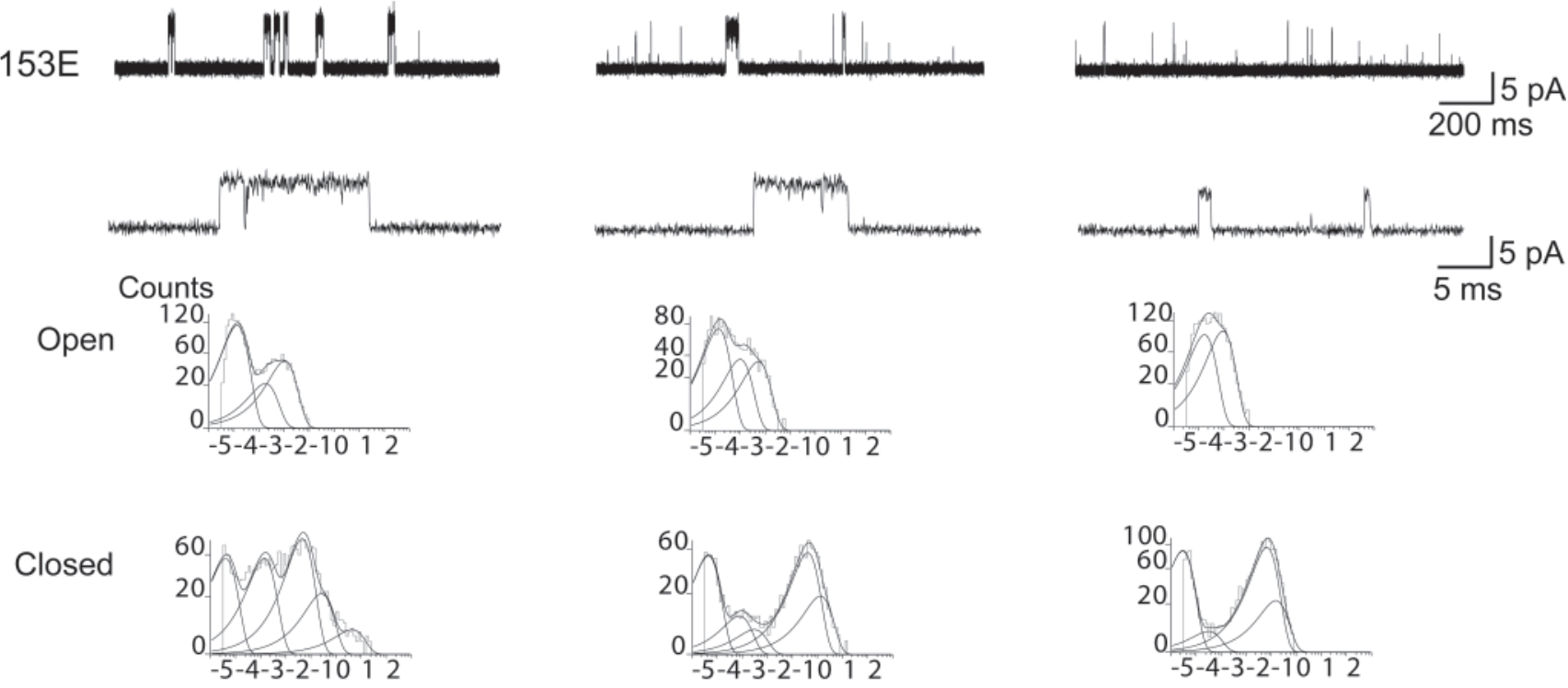
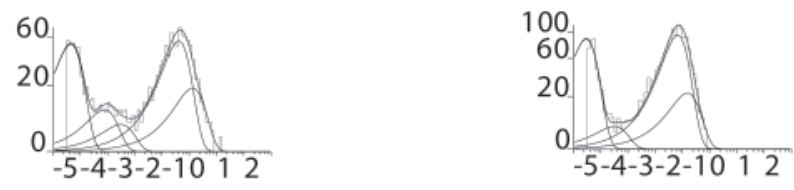

$\log$ Duration (s)

Fig. 8. Single-channel currents of $\alpha 7-5 \mathrm{HT}_{3 \mathrm{~A}}$ carrying the mutation G153E. Channels activated by $10 \mu \mathrm{M}$ ACh, $1 \mu \mathrm{M}$ pyrantel, and $100 \mu \mathrm{M}$ levamisole were recorded from cells expressing the mutant $\alpha 7-\mathrm{G} 153 \mathrm{E}-5 \mathrm{HT}_{3 \mathrm{~A}}$ receptor. Traces of currents are displaced at a bandwidth of $10 \mathrm{kHz}$ with channel openings as upward deflections. Open- and closed-time histograms corresponding to each condition are shown. Membrane potential, $-70 \mathrm{mV}$. 
ing two open and two closed states describes activation of receptors with the optimal number of agonist sites occupied (Rayes et al., 2005). The same cyclic scheme with two additional blocked states well describes the activation by pyrantel, which shows rate constants similar to those of ACh activation. The analysis indicates that once fully occupied by pyrantel, the receptor opens efficiently and closes and reopens several times, undergoing transitions mainly through $\mathrm{C} 1, \mathrm{O} 1$, and $\mathrm{O} 2$ states.

Structural Basis for the High Selectivity of Pyrantel for $\boldsymbol{\alpha} 7$. The differences in the potency of pyrantel among AChR subtypes may result from differences in the affinity or in their ability to open the channel once bound (efficacy). Making the distinction between effects on binding and effects on conformational change is not easy (Colquhoun, 1998). Therefore, residues involved in the selectivity of pyrantel for $\alpha 7$ could be located anywhere in the receptor. We here focused on residues located at the complementary face of the binding site, which show poor conservation between $\alpha 7$ and the muscle $\varepsilon$ subunit. Mutations at residues $\alpha 7-$ Asn 111 and $\alpha 7-G \ln 117$ slightly decrease the potency for activation by $\mathrm{ACh}$ and pyrantel in a quantitatively similar manner, indicating that they do not govern pyrantel selectivity. The equivalent residues in the Torpedo AChR, $\gamma$ Tyr111 and $\gamma$ Tyr117, were reported to interact with $d$-tubocurarine (Chiara et al., 1999; Willcockson et al., 2002). Thus, it is possible that mutations at these residues affect only the affinity for agonists. The mutation G167A does not affect the sensitivity to either ACh or pyrantel, but it has been shown previously to be involved in the sensitivity of $\alpha 7$ to imidacloprid (Matsuda et al., 2000).

The mutation Q57G selectively decreases the efficacy for activation by pyrantel without affecting activation by $\mathrm{ACh}$. At the macroscopic current level, such a decrease was revealed by the decrease in the maximum peak current elicited by pyrantel, an increase in the $\mathrm{EC}_{50}$ value, and a decrease in the Hill coefficient. In contrast, dose-response curves for ACh do not change in the mutant with respect to the control chimera. The reduction in the Hill slope indicates an impairment of gating (Colquhoun, 1998), and it would not be expected if the residue were affecting only binding affinity of the resting state (Spier and Lummis, 2000). At the singlechannel level, no changes are observed in Q57G channels activated by $\mathrm{ACh}$ with respect to the control ones. In contrast, in the presence of pyrantel, a dramatic reduction of the burst duration is observed. Such reduction may be due to changes in the agonist-dissociation rate, in channel gating, and/or desensitization. Because of the absence of closed components sensitive to agonist concentration, it is not possible to evaluate the binding steps in our kinetic analysis of $\alpha 7$ $5 \mathrm{HT}_{3 \mathrm{~A}}$ (Rayes et al., 2005). Therefore, we cannot determine whether the mutation $\alpha 7-\mathrm{Q} 57 \mathrm{G}$ affects agonist dissociation. Macroscopic currents do not show significant changes in the decay rates, thus discarding important changes in desensitization. Nevertheless, the kinetic analysis reveals profound changes in channel gating. The cyclic scheme can be simplified to a linear one containing only one open (O2), one closed (C1), and a blocked state. It is interesting to note that in the control $\alpha 7-5 \mathrm{HT}_{3 \mathrm{~A}}$ chimera, the brief openings within bursts (O1) correspond to approximately $30 \%$ of the total openings, and that in the mutant chimera, the peak current shows a decrease of approximately $40 \%$. Given that C1 is the most likely state linking binding to channel opening steps (Rayes et al., 2005), it is therefore possible that the reduction in the peak current is mainly due to the fact that the C1-to-O1 transition has a low probability to occur ( $\beta 1$ decreases 4000 fold). The remaining current may correspond to the C1-to-O2 transition, which is not significantly affected in the Q57G mutant.

Although the molecular interactions that result in partial agonism are not yet understood, we here show that a glycine at position 57, which is found in the muscle AChR, converts pyrantel into a partial agonist by affecting the way in which it couples binding to channel gating. The same position has been shown to be involved in the sensitivity of $\alpha 7$ to neonicotinoid insecticides (Shimomura et al., 2002).

The mutation $\alpha 1-$ G153E increases the efficacy of levamisole as an agonist of mammalian muscle AChRs (Rayes et al., 2004). A glutamic acid is found in $\alpha$ subunits of nematode muscle, such as UNC-38, $\alpha 1$ A. suum, TAR1 T. colubriformis, and it could be involved in the high efficacy of levamisole at nematode AChRs. This residue is located at loop B, which contributes to the principal face of the ACh binding pocket in the $\alpha 1$ subunit (Brejc et al., 2001). Our results show that, as in the muscle AChR, the $\alpha 7-\mathrm{G} 153 \mathrm{E}$ mutation increases the potency for activation by ACh and anthelmintics and that the increase is selectively higher for the latter drugs than for $\mathrm{ACh}$. These results agree with those reported by Grutter et al. (2003), showing that the mutation G153K increases the potency and the affinity for different ligands in a selective manner.

The experiments with the Q57G-G153E double mutant enlighten the contribution of both residues to anthelmintic activation. The results reveal that activation by $\mathrm{ACh}$ or levamisole is affected by the residue at position 153 but not by that located at position 57. In contrast, both positions are similarly involved in pyrantel activation. Extrapolated to the nematode AChR, these findings suggest that mutations at specific residues, such as Gln57, may affect the sensitivity to a specific anthelmintic, such as pyrantel. This could be a possible explanation for the observation that under pyrantel treatment of pigs infested with Oesophagostomum species, the nematodes acquire resistance to this anthelmintic but not to levamisole (Bjorn et al., 1990).

Our results reveal that the maximum sensitivity to pyrantel would be achieved when the AChR contains both a glutamic acid at position 153 (principal face) and a glutamine at position 57 (complementary face). The minimum sensitivity would be achieved in the receptor containing glycine at both positions (Gly57 and Gly153), which corresponds to the mammalian muscle AChR. It remains to be determined whether there is either a muscle levamisole-sensitive AChR, which is also sensitive to pyrantel, composed of UNC-38, UNC-63, UNC-29, and LEV-1, or more than one receptor, each made from various combinations of subunits (Culetto et al., 2004). We compared the sequences of $C$. elegans $\alpha$ and non- $\alpha$ subunits that may form levamisole-sensitive AChRs. On the basis of our results, we speculate that Glu153 is provided by UNC-38 and Gln57 by UNC-63, and that this combination leads to receptors highly sensitive to pyrantel.

\section{References}

Akk G, Bracamontes J, and Steinbach JH (2004) Activation of $\mathrm{GABA}_{\mathrm{A}}$ receptors containing the alpha4 subunit by GABA and pentobarbital. $J$ Physiol 556:387399. 
Akk G, Milescu LS, and Heckmann M (2005) Activation of heteroliganded mouse muscle nicotinic receptors. J Physiol 564:359-376.

Bjorn H, Roepstorff A, Waller PJ, and Nansen P (1990) Resistance to levamisole and cross-resistance between pyrantel and levamisole in Oesophagostomum quadrispinulatum and Oesophagostomum dentatum of pigs. Vet Parasitol 37:2130 .

Bouzat C, Barrantes F, and Sine S (2000) Nicotinic receptor fourth transmembrane domain: hydrogen bonding by conserved threonine contributes to channel gating kinetics. J Gen Physiol 115:663-672.

Bouzat C, Bren N, and Sine SM (1994) Structural basis of the different gating kinetics of fetal and adult nicotinic acetylcholine receptor. Neuron 13:1395-1402

Bouzat C, Gumilar F, Esandi MC, and Sine SM (2002) Subunit-selective contribution to channel gating of the M4 domain of the nicotinic receptor. Biophys $J$ 82:19201929 .

Bouzat C, Gumilar F, Spitzmaul G, Wang HL, Rayes D, Hansen SB, Taylor P, and Sine SM (2004) Coupling of agonist binding to channel gating in an ACh-binding protein linked to an ion channel. Nature (Lond) 430:896-900.

Brejc K, van Dijk WJ, Klaassen RV, Schuurmans M, van Der Oost J, Smit AB, and Sixma TK (2001) Crystal structure of an ACh-binding protein reveals the ligandbinding domain of nicotinic receptors. Nature (Lond) 411:269-276.

Chiara DC, Xie Y, and Cohen JB (1999) Structure of the agonist-binding sites of the Torpedo nicotinic acetylcholine receptor: affinity-labeling and mutational analyse identify gamma Tyr-111/delta Arg-113 as antagonist affinity determinants. Biochemistry 38:6689-6698.

Colquhoun D (1998) Binding, gating, affinity and efficacy: the interpretation of structure-activity relationships for agonists and of the effects of mutating receptors. Br J Pharmacol 125:924-947.

Culetto E, Baylis HA, Richmond JE, Jones AK, Fleming JT, Squires MD, Lewis JA and Sattelle DB (2004) The Caenorhabditis elegans unc-63 gene encodes a levamisol-sensitive nicotinic acetylcholine receptor $\alpha$ subunit. J Biol Chem 279:4247642483

Eisele J-L, Bertrand S, Galzi J-L, Devillers-Thiery A, Changeux J-P, and Bertrand D (1993) Chimaeric nicotinic-serotoninergic receptor combines distinct ligand binding and channel specificities. Nature (Lond) 366:479-483.

Grutter T, Prado de Carvalho L, Le Novere N, Corringer PJ, Edelstein S, and Changeux JP (2003) An H-bond between two residues from different loops of the acetylcholine binding site contributes to the activation mechanism of nicotinic receptors. EMBO (Eur Mol Biol Organ) J 22:1990-2003.

Hamill OP, Marty A, Neher E, Sakmann B, and Sigworth FJ (1981) Improved patch-clamp techniques for high-resolution current recording from cells and cellfree membrane patches. Pflueg Arch Eur J Physiol 391:85-100.

Jones A and Sattelle D (2003) Functional genomics of the nicotinic acetylcholine receptor gene family of the nematode, Caenorhabditis elegans. Bioessays 26.1:3949.

Kelley S, Dunlop J, Kirkness E, Lambert J, and Peters J (2003) A cytoplasmic region determines single-channel conductance in 5-HT3 receptors. Nature (Lond) 424: 321-324.

Le Novére N and Changeux JP (2001) The Ligand Gated Ion Channel database: an example of a sequence database in neuroscience. Philos Trans $R$ Soc Lond B Biol Sci 356:1121-1130.

Lester HA, Dibas MI, Dahan DS, Leite JF, and Dougherty DA (2004) Cys-loop receptors: new twists and turns. Trends Neurosci 27:329-336.
Liu Y and Dilger JP (1991) Opening rate of acetylcholine receptor channels. Biophys $J$ 60:424-432.

Martin RJ, Walkanov MA, Dale VM, Robertson AP, and Murray I (1996) Electrophysiology of Ascaris muscle and anti-nematodal drug action. Parasitology 113 S137-S156.

Matsuda K, Shimomura M, Kondo Y, Ihara M, Hashigami K, Yoshida N, Raymond V, Mongan NP, Freeman JC, Komai K, et al. (2000) Role of loop D of the $\alpha 7$ nicotinic acetylcholine receptor in its interaction with the insecticide imidacloprid and related neonicotinoids. Br J Pharmacol 130:981-986.

Neher E and Steinbach JH (1978) Local anaesthetics transiently block currents through single acetylcholine receptor channels. J Physiol 277:153-176.

Putrenko I, Zakikhani M, and Dent JA (2005) A family of acetylcholine-gated chloride channel subunits in Caenorhabditis elegans. J Biol Chem 280:6392-6398. Qin F, Auerbach A, and Sachs F (1996) Estimating single-channel kinetic parameters from idealized patch-clamp data containing missed events. Biophys $J$ 70:264 280

Rayes D, De Rosa MJ, Bartos M, and Bouzat C (2004) Molecular basis of the differential sensitivity of nematode and mammalian muscle to the anthelmintic agent levamisole. J Biol Chem 279:36372-36381.

Rayes D, De Rosa MJ, Spitzmaul G, and Bouzat C (2001) The anthelmintic pyrantel acts as a low efficacious agonist and an open-channel blocker of mammalian acetylcholine receptors. Neuropharmacology 41:238-245.

Rayes D, Spitzmaul G, Sine S, and Bouzat C (2005) Single-channel kinetic analysis of chimaeric $\alpha 7-5 \mathrm{HT}_{3 \mathrm{~A}}$ receptors. Mol Pharmacol 68:1475-1483.

Richmond JE and Jorgensen EM (1999) One GABA and two acetylcholine receptors function at the $C$. elegans neuromuscular junction. Nat Neurosci 2:791-797.

Shimomura M, Okuda H, Matsuda K, Komai K, Akamatsu M, and Sattelle DB (2002) Effects of mutations of a glutamine residue in loop D of the $\alpha 7$ nicotinic acetyl choline receptor on agonist profiles for neonicotinoid insecticides and related ligands. Br J Pharmacol 137:162-169.

Sigworth F and Sine SM (1987) Data transformation for improved display and fitting of single-channel dwell time histograms. Biophys $J$ 52:1047-1052.

Sine SM (2002) The nicotinic receptor ligand binding domain. J Neurobiol 53:431446.

Spier AD and Lummis SC (2000) The role of tryptophan residues in the 5-hydroxytryptamine ${ }_{3}$ receptor ligand binding domain. J Biol Chem 275:5620-5625.

Spitzmaul G, Dilger JP, and Bouzat C (2001) The noncompetitive inhibitor quinacrine modifies the desensitization kinetics of muscle acetylcholine receptors. $\mathrm{Mol}$ Pharmacol 60:235-243.

Steinbach JH and Chen Q (1995) Antagonist and partial agonist actions of dtubocurarine at mammalian muscle acetylcholine receptors. J Neurosci 15:230 240.

Wang HL, Auerbach A, Bren N, Ohno K, Engel AG, and Sine SM (1997) Mutation in the M1 domain of the acetylcholine receptor alpha subunit decreases the rate of agonist dissociation. J Gen Physiol 109:757-766.

Willcockson IU, Hong A, Whisenant RP, Edwards JB, Wang H, Sarkar HK, and Pedersen SE (2002) Orientation of d-tubocurarine in the muscle nicotinic acetylcholine receptor-binding site. J Biol Chem 277:42249-42258.

Address correspondence to: Dr. Cecilia Bouzat, Instituto de Investigaciones Bioquímicas, Camino La Carrindanga $\mathrm{Km}$ 7, B8000FWB, Bahía Blanca, Argentina. E-mail: inbouzat@criba.edu.ar 